\title{
Influence of environmental factors on food intake among nursing home residents: a survey combined with a video approach
}

\author{
Fanny Buckinx' \\ Jean-Yves Reginster' \\ Alison Morelle ${ }^{2}$ \\ Nicolas Paquot ${ }^{3}$ \\ Nicole Labeye ${ }^{3}$ \\ Médéa Locquet ${ }^{1}$ \\ Stéphane Adam ${ }^{4, *}$ \\ Olivier Bruyère ${ }^{1,5, *}$ \\ 'Department of Public Health, \\ Epidemiology and Health Economics, \\ University of Liège, ${ }^{2}$ Nutrition \\ and Dietetics, Haute Ecole de \\ la Province de Liège, ${ }^{3}$ Diabetes, \\ Nutrition and Metabolic Diseases, \\ University Teaching Hospital of \\ Liège, ${ }^{4}$ Psychology of Senescence, \\ ${ }^{5}$ Department of Sport Sciences and \\ Rehabilitation, University of Liège, \\ Liège, Belgium \\ *These authors contributed equally \\ to this work
}

This article was published in the following Dove Press journal:

Clinical Interventions in Aging

4 July 2017

Number of times this article has been viewed

Background: In addition to the well-known physiological factors, dietary behavior that affects health seems to be influenced by a wide variety of environmental factors. The aim of this study was to assess, by means of an original video approach, the influence of the environment on food intake in nursing homes.

Methods: The perception of the environment during meals in nursing homes was evaluated by residents and by two groups of volunteers who either work in the field of geriatrics, or who do not work in the field of geriatrics. First, a random sample of residents answered a self-administered questionnaire related to different indicators (ie, noise, space, comfort, light, odors, perceived satisfaction of meals, taste of meals, presentation of meals, service and setting). Second, two separate panels, one including the people who work in the field of geriatrics (ie, experts) and one including the people who have no particular interest in geriatrics (ie, nonexperts), were asked to answer a questionnaire on their perception of the environment after having watched a video of the lunch in each nursing home. Then, the food intake of the residents was measured by a precise food-weighing method.

Results: A total of 88 residents from nine different nursing homes, 18 experts and 45 nonexperts answered the questionnaires. This study highlighted that, on the one hand, after adjustment on confounding variables, the perception of the quantity of food served by the residents is the only single factor associated with food consumption $(P=0.003)$. On the other hand, experts and nonexperts did not perceive any environmental factor that seems to be significantly associated with residents' food intake.

Conclusion: Our results highlighted that, in a nursing home setting, environmental factors have limited influence on the food intake of the residents, with the exception of their own perception of the quantity served. The relevance of this factor deserves further investigation.

Keywords: nutritional intake, older persons, institution, meal environment

\section{Introduction}

Among the elderly, the decline in food intake and the loss of motivation to eat are widely reported. ${ }^{1}$ Malnutrition in nursing homes is increasingly recognized as a major international research priority, given the expanding geriatric populations, serious consequences and challenges conducting research in nursing homes. ${ }^{2}$ Indeed, malnutrition leads to poor health, functional impairment, decreased quality of life and increased mortality. ${ }^{3}$ Malnutrition prevalence in the hospital (acute) setting has been widely documented in the literature and is found to be between $20 \%$ and $50 \%{ }^{4}$ In community-dwelling older adults, the reported prevalence is between $5 \%$ and $30 \%$, whereas the prevalence ranged between $16 \%$ and $70 \%$ in the residential aged care home setting. ${ }^{5}$ In Belgium, $29 \%$ of adult patients receiving nursing care at home are at risk 
for malnutrition. ${ }^{6}$ A total of $33 \%$ of Belgian elderly hospital patients suffered from malnutrition. ${ }^{7}$ In the nursing home setting, $38.7 \%$ of Belgian residents were at risk for malnutrition and $19.4 \%$ were malnourished. ${ }^{8}$ Malnutrition prevalence rates increase with age ${ }^{9}$ due to factors such as multi-morbidity, decreased appetite, diminished physical functions, oral health, the ability to eat alone or with help, and/or cognitive decline. ${ }^{10}$ In addition to these physiological factors, dietary behavior that affects health seems to be influenced by a wide variety of environmental factors. ${ }^{11,12}$ At present, a few studies have investigated the influence of the environment on food intake. Elmstahl et $\mathrm{al}^{13}$ studied 16 geriatric patients before, during and after a changed meal environment in a long-term care ward. During the experimental period, the intake of energy and protein increased by $25 \%(P<0.001)$. The eating environment refers to the social interactions, the distractions that may be taking place, the salience of the food, its structure, its portion size, how it is served, ${ }^{11}$ etc. As Meiselman ${ }^{14}$ has argued, there is abundant research investigating sensory and internal physiological mechanisms in controlling food intake, but the possibility of other situational and social factors has been largely ignored. However, intuitively, this parameter seems important (eg, during a dinner in a restaurant, the context plays a role in the pleasure to eat). Objective, observational measurements of nutrition environments are poorly investigated. Color, light, sound and odor are all factors that could affect physical and emotional wellbeing. ${ }^{15}$ Such measurements of the nutrition environment are also believed to have an important influence on food choice and dietary intake. ${ }^{16}$

Recent research evaluating the perceived food environment has been qualitative or focused on a small number of items, limiting interpretation. ${ }^{17}$ Moreover, few studies focused on people's perceptions of their own nutrition environments. Yet, this self-perception seems to play a role in food intake or nutritional status. ${ }^{16}$ Consequently, more research is needed on the relationship between perceptions and health behavior. In addition, these studies were performed among different populations and settings (ie, midlife women residing in rural and urban areas, ${ }^{17}$ healthy adults ${ }^{18}$ and children ${ }^{19}$ ) but rarely among elderly people, particularly in nursing homes. Nevertheless, the perception of the environment during meals is probably different in a nursing home compared with elsewhere in the community.

Based on the previous findings, the aim of this study was to investigate the influence of the psychoemotional dimension on food intake among nursing home residents. To do this, we used an original methodology consisting of an analysis on the perception of residents, volunteers who work in the field of geriatrics, and volunteers who have no particular interest in geriatrics, concerning the environment during meals in the institution. Volunteers (ie, experts and nonexperts) were asked to complete a survey after watching a video of meal time in the nursing homes, and residents also completed a self-administered questionnaire. Residents' food consumption was measured using a precise food-weighing method.

\section{Methods Design of the study}

This study was conducted in nursing homes in and around Liège, Belgium, between November 2015 and May 2016. The protocol was approved by the ethics committee of the University Teaching Hospital of Liège under the number $2015 / 161$. Because of the video recording, this research has some ethical implications. The closely filmed residents signed an informed consent form before the beginning of the study. In addition, the faces of the other residents were blurred in the video recording on the overview of the room. Ultimately, this video was only meant to assess the context of meal time (ie, noise, brightness, etc.).

\section{Population and setting}

First, a random sample of residents from the nine nursing homes were eligible for the study if they agreed to participate and signed the informed consent form (ie, 10 participants from each nursing home). In Belgium, a nursing home is defined as a long-term care facility that offers 24 -hour room and board and health care services, including basic and skilled nursing care, rehabilitation, and a full range of other therapies, treatments and programs. Informed consent was obtained from all participants prior to their participation in the study. To be included in this study, patients had to be older than 65 years, because this study is focused on geriatric patients, had to be oriented (able to consent) and should take their lunch in the dining room. Participants were excluded if they were fed enterally or parenterally. Participants having a modified texture diet were also excluded (it would have been impossible to accurately weigh foods separately if residents were fed enterally or parenterally or if they had a modified texture diet). Finally, residents requiring assistance at meal times were excluded because the questionnaire was not adapted for this population. Among the patients eligible for this study, a computer randomization by block of four was performed, in order to select 10 participants in each nursing home. The number of 10 residents was chosen for 
feasibility reasons. It is the maximum number of meals that could precisely be weighed during a single meal time.

Then, a panel of volunteers who worked in the field of geriatrics (ie, experts in geriatrics such as physicians, nurses and dietitians) were asked to participate in our study. These individuals were recruited by emails sent to different institutions (ie, geriatric units from hospitals and nursing homes). Finally, a sample of volunteers who had no particular interest in geriatrics (ie, nonexperts) was recruited via social networks.

\section{Data collected}

\section{Information about the meals in nursing homes}

In order to characterize the setting, the director of each nursing home was interviewed to gather information about the organization of meals in the institution. The questionnaire included 12 closed questions regarding the number of meals served per day, the place where the meals are prepared (ie, within or outside the institution), rolling daily menus, seasonal menus, the possibility of an alternative menu according to the resident's food taste, the particular diet imposed on the residents (ie, high-calorie diet, diabetic menu, low-salt diet, lactose-free diet, mixed diet, renal failure diet, etc), the adaptation of portions to the appetite of the residents (or standard portions), the place where the meal is served (ie, at table or buffet), any defined seating plan, the dinner schedules - fixed or variable, whether television or radio is turned on during the meal and whether visitors have the opportunity to eat with the residents.

\section{Food intake}

Food served and food actually consumed by residents during dinner were evaluated by a precise food-weighing method, over a 3 -day period..$^{20}$ The results were averaged over the 3 days. Food consumption was calculated on the basis of the difference between the weight of the food served and that not consumed by the subjects. ${ }^{21}$ The plates were weighed prior to being served and at the end of the meal. Thus, the amount (ie, in grams and percent) of food actually consumed was measured. Weighing was performed using scales with an accuracy of $1 \mathrm{~g}$. Weighing food is a very accurate method; however, it involves complex operations in a real-life setting (ie, nursing home) as it requires coordinating the management of food distribution with the data collection. Furthermore, this method is time consuming.

\section{Environment during the meal Video approach}

The "meal time" was filmed in nine nursing homes for 3 days. The film realized on the third day was considered for the analysis. Two cameras were placed in the dining room: the first one filming a 5-minute overview and the second one to closely film one resident and his/her plate for 3 minutes. Thus, among a total of 54 video clips, 18 video clips (ie, two in each nursing home: one overview of the dining room and one specific view of one resident) were used for the analysis. The filmed resident in each nursing home was randomly selected, and the participants from the different nursing homes were matched for several clinical characteristics (ie, age, sex, body mass index [BMI], cognitive status and level of dependence). The positioning of the cameras was standardized, back to the windows. A 30-second video compilation for each nursing home (ie, 15 seconds for the overview and 15 seconds for the resident) was produced. Short video sequences were chosen to limit experts' response time (30 seconds for each nursing home) to the questionnaire in order to avoid, as much as possible, nonresponse or incomplete answers. This video footage was shown to the experts and the general population in a random order. The film of the overview was shown to the judges before the video of the resident, to avoid influencing their answers by the attitude of the residents during the meal time.

\section{Questionnaire for residents}

Residents answered a self-administered questionnaire regarding their own perception of the environment. This questionnaire included closed questions requiring an answer "yes" or "no" (ie, cosy dining room, noisy dining room, spacious dining room, comfortable dining room, brightly lit dining room, and good smell in the dining room). The questionnaire also included visual analog scales (VASs) about the satisfaction of the meal, the satisfaction of the setting, the temperature of the meal, the quantity served, the diversity of the meals, the taste of the meals, the presentation of the dish, and the quality of the service. To create this questionnaire, two researchers (FB and AM), performed an exhaustive literature review on PubMed database to identify the environmental factors that could influence the food intake in the general population (item generation). Based on these findings, a discussion with experts in the fields of geriatrics, psychology and public health was organized to select the most relevant items to include in the questionnaire (item reduction). The first version of the questionnaire was developed and pretested among five nursing home residents who were not included in the study (pretest of the questionnaire). The questionnaire was answered without major difficulties by the residents. Thus, the final version of the questionnaire was distributed to the study sample. 
Questionnaire for volunteers who work in the field of geriatrics and those who have no particular interest in geriatrics

After watching videos, the panel of volunteers from experts in geriatrics and nursing homes, and the panel of nonexperts, were asked to answer a questionnaire related to their own perception of the meal time in each nursing home. The questionnaire was composed of six items (ie, pleasant setting, the desire to eat in this place, staff attitude during the meal, the noise, the appetizing aspect of the meal, and the resident seems to enjoy eating) and took the form of a VAS. Note that the videos of the nursing homes were presented in a random order to the experts. Our questionnaire was developed according to the following four steps:

- Step 1. Item generation - based on literature review,

- Step 2. Item reduction - based on "experts" relevance ranking,

- Step 3. Questionnaire generation - developed during an expert meeting, and

- Step 4. Pretest of the questionnaire - based on sarcopenic subjects' opinions.

\section{Statistical analysis}

The power calculation was based on two previous studies that showed that the environment could modify food intake among elderly by $7 \%{ }^{15}-25 \%{ }^{13}$ The mean value of $16 \%$ was chosen for the calculation. Previous results indicating that the mean energy food intake of nursing home residents was $1,552.4 \pm 342.1 \mathrm{kcal}$ per day ${ }^{22}$ were also used. Using a statistical power of $90 \%$ and a risk $\alpha$ of 0.05 , a minimum of 84 participants were needed to ensure sufficient statistical power in our analysis.

Quantitative variables were expressed as the mean \pm standard deviation (SD), and qualitative ones were expressed in frequencies (\%). Shapiro-Wilk test verified the normal distribution of all parameters. Because the quantity of food served is probably different from one nursing home to another, it was decided to use an absolute value (ie, grams). However, when the statistical analyses were performed on the quantity of food consumed (grams) or on the percentage of food consumed in relation to the quantity served (\%), the results followed the same trend. The influence of the environment on the quantity of food consumed was assessed by means of multiple regressions adjusted on confounding factors related to the patients themselves (ie, age and sex) and to the setting (ie, variables relating to the organization of meals in nursing homes). Quantitative variables were compared between groups using Student's $t$-test or analysis of variance (ANOVA) when appropriate. The relationship between several quantitative variables was assessed by means of correlation. For each item which the experts and the nonexperts answered, we grouped the nine nursing homes into tertiles according to the score given (ie, three lower scored, three intermediate scored and three higher scored). The concordance between their opinions (ie, internal consistency) was assessed by means of alpha's Cronbach coefficient. The alpha value ranged from 0 to 1 , and internal consistency increased as alpha approached 1 . A coefficient value $>0.70$ indicated a high level of internal consistency. ${ }^{23}$

The data analyses were performed using Statistica 12 software. The results were considered as statistically significant when the two-tailed $P$-values were $<0.05$.

\section{Results}

\section{Population}

The director of each nursing home answered a questionnaire about the organization of meals in their institutions. Characteristics of the meals in the nine studied nursing homes are summarized in Table 1.

\section{Perception of the environment by the residents}

A total of 88 residents aged $79.9 \pm 15.7$ years $(65.9 \%$ of women) were enrolled in this analysis. In all, $58.9 \%$ of the

Table I Details on the organization of meals provided by the director of each nursing home

\begin{tabular}{|c|c|c|}
\hline Characteristics & Response & Number (\%) \\
\hline Number of meals served & 4 & 8 (88.9) \\
\hline per day & 3 & I (II.I) \\
\hline \multirow[t]{2}{*}{ Preparation of the meals } & On site & $5(55.6)$ \\
\hline & $\begin{array}{l}\text { External to the } \\
\text { institution }\end{array}$ & $4(44.4)$ \\
\hline Rolling daily menus & Yes & $5(55.6)$ \\
\hline Seasonal menus & Yes & $9(100)$ \\
\hline Possibility of an alternative & Based on medical history & $8(88.9)$ \\
\hline $\begin{array}{l}\text { menu according to the } \\
\text { resident's food taste? }\end{array}$ & Taste sheet & I (II.I) \\
\hline Particular diet imposed on & High-calorie diet & I (II.I) \\
\hline residents & Low-salt diet & $2(22.2)$ \\
\hline Dinner is served at the table & Yes & $7(77.8)$ \\
\hline $\begin{array}{l}\text { Served portion adapted to } \\
\text { each resident (or standard } \\
\text { portions) }\end{array}$ & Yes & $9(100)$ \\
\hline The seating plan is defined & Yes & $9(100)$ \\
\hline Is the dinner at fixed times? & Yes & $6(66.7)$ \\
\hline Television or radio are & Radio & $2(22.2)$ \\
\hline turned on during the dinner & TV & I (II.I) \\
\hline $\begin{array}{l}\text { Visitors have the opportunity } \\
\text { to eat with the resident }\end{array}$ & Yes & $9(100)$ \\
\hline
\end{tabular}


residents were excluded from the study because of the exclusion criteria (ie, $3 \%$ were disoriented, $34.5 \%$ had a modified texture diet, $3.7 \%$ were fed enterally or parenterally, and $17.7 \%$ did not take their lunch in the dining room).

The environment perceived by the residents themselves seems to have little influence on their food intake. After adjustment on age, sex and variables related to the organization of the meals, presented in Table 1, there were no significant differences in food consumption between the participants who positively perceived the environment, and those who judged it negatively, according to certain criteria: cosy dining room, noisy dining room, spacious dining room, comfortable dining room, brightly lit dining room and smell of the dining room ( $P$-values $0.48,0.54,0.08,0.82,0.76$ and 0.88 , respectively; Table 2 ). In addition, no significant correlations were observed between the quantity of food consumed by the residents and their own satisfaction with the meal served $(r=0.09 ; P=0.40)$, perception of the setting ( $r=-0.21, P=0.06$ ), perception of the diversity of the meals ( $r=0.12, P=0.27)$, perception of the taste $(r=0.11, P=0.33)$, perception of the presentation $(r=0.13, P=0.24)$ and perception of the service $(r=-0.01, P=0.89)$.

In univariate analyses, two environmental factors were associated with residents' food intake. The first one was the perception of the quantity served $(r=-0.32, P=0.003)$ and the second one was the perception of the temperature of the meals $(r=-0.05, P=0.04)$. In multivariate analyses, when the influence of all the confounding factors (ie, age, sex, and the variables relating to the organization of the meals, presented in Table 1) on residents' food intake are taken into account, through multiple regression $\left(R^{2}\right.$ adjusted $\left.=0.08 ; P<0.0001\right)$, the perception of the quantity served is the only significant factor influencing the food intake $(\beta=-18.2, P=0.04)$. The perception of the quantity served, judged by the residents, was assessed by means of a VAS ranging between "insufficient" and "too abundant". Their perception was thus separated into three groups according to the tertiles (below P25, between P25 and P75, and above P75). As shown in Figure 1, the more the quantity served is perceived as large by the residents, the less they eat.

\section{Perception of the environment by people who work in the field of geriatrics}

According to a scale ranging from $0 \%$ to $100 \%$ (ie, $0=$ not at all, and 100=absolutely), the 18 experts enrolled in this study (mean age of $35.4 \pm 9.13$ years with $77.8 \%$ women) judged the environment of the dining room based on different factors:

- pleasant setting: $60.8 \%$ (min-max: $35.1 \%-64.1 \%$ ),

- the desire to eat in the nursing homes concerned: $55.9 \%$ (min-max: 29.1\%-57.8\%),

- the staff who served: $62.3 \%$ (min-max: 48.1\%-68.3\%),

- the noise: $53.3 \%$ (min-max: $40.7 \%-62.9 \%$ ),

- the dish looked appetizing: 57.5\% (min-max: 40.8\%$63.7 \%$ ), and

- the resident seems to enjoy eating: 54.8\% (min-max: $31.5 \%-66.6 \%)$.

The opinion of the experts, regarding these six items, is concordant. Indeed, the Cronbach's alpha values were 0.83 , $0.87,0.83,0.89,0.86$ and 0.86 , respectively.

When comparing the quantity of food consumed by the residents between the three groups of nursing homes, based on the scores assigned by the experts according to the environmental factors mentioned earlier, no environmental factor seems to influence the quantity of food consumed by the residents, after adjustment for confounding variables $\left(R^{2}\right.$ adjusted $=0.76 ; P$-value $=0.20 ;$ Table 3$)$.

The food consumption was not significantly different between the two extreme groups (ie, lower scored nursing

Table 2 Differences in quantity of food consumed (grams) between residents who positively perceived the environment and those who judged it negatively according to six criteria

\begin{tabular}{lllr}
\hline Criteria & $\begin{array}{l}\text { Mean } \pm \text { SD of the food consumed } \\
\text { (grams) among residents who } \\
\text { positively perceived the environment }\end{array}$ & $\begin{array}{l}\text { Mean } \pm \text { SD of the food consumed } \\
\text { (grams) among residents who } \\
\text { negatively perceived the environment }\end{array}$ \\
\hline Cozy dining room & $303.5 \pm 125.7$ & $270.4 \pm 43.2$ & 0.48 \\
Noisy dining room & $316.3 \pm 158.6$ & $296.0 \pm 105.1$ & 0.54 \\
Spacious dining room & $371.5 \pm 202.8$ & $291.8 \pm 105.0$ & 0.08 \\
Comfortable dining room & $300.8 \pm 125.8$ & $319.8 \pm 104.1$ & 0.82 \\
Brightly lit dining room & $303.1 \pm 126.4$ & $287.3 \pm 51.1$ & 0.76 \\
Smell in the dining room & $301.7 \pm 127.6$ & $312.9 \pm 418.0$ & 0.88 \\
\hline
\end{tabular}

Note: *P-value adjusted on the variables related to the organization of the meals presented in Table I: number of meals served per day, preparation of the meal on site or external to the institution, rolling daily menus, seasonal menus, possibility of alternative menus, diet imposed, dinner served at the table, adapted portions, seating plan, fixed times for dining, presence of TV or radio during the dinner, and possibility of having visits during the dinner. 


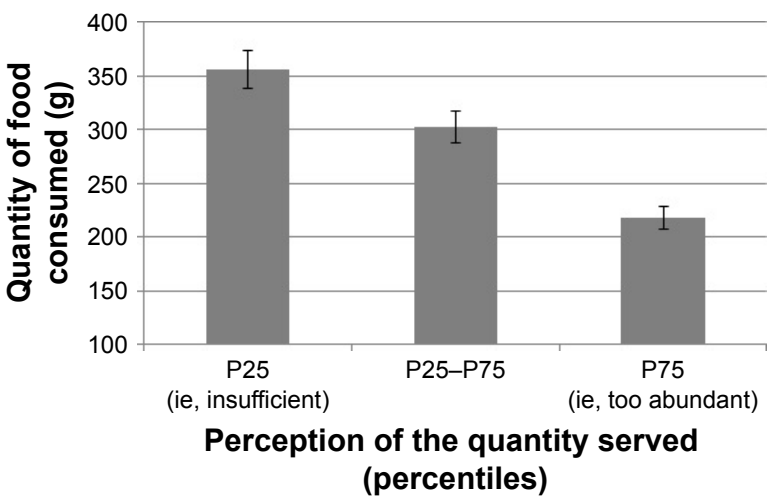

Figure I Quantity of food consumed by the residents according to their perception of the quantity served.

homes and higher scored nursing homes) for the six studied parameters $(P$-values $=0.35,0.06,0.036,0.30,0.31$ and 0.82 , respectively).

\section{Perception of the environment by people who have no particular interest in geriatrics}

A panel of 45 nonexperts aged $32.8 \pm 15.7$ years and composed of $81.6 \%$ women participated in this study. Globally, the nonexperts judged the dining room of the different nursing homes as follows: $60.2 \%$ considered it to be pleasant (minmax: $48 \%-62.5 \%), 55.2 \%$ expressed the desire to eat in these nursing homes (min-max: 34.3\%-69\%) - they judged the staff who served at $64.5 \%(44.1 \%-73.1 \%)$, noise was estimated at 53.3\% (min-max: $38.3 \%-68 \%$ ), the dish was judged to be appetizing by $55.7 \%$ (min-max: $39.2 \%-62.2 \%$ ) and $54 \%$ considered that the residents seemed to enjoy eating (min-max: 30.9\%-63.7\%). For these six items, we observed a high internal consistency between the nonexperts' opinions. Indeed, the Cronbach's alpha values were 0.84, 0.88, 0.80, $0.87,0.88$ and 0.87 , respectively. Also note that the opinion of the nonexperts regarding the six studied items was very close to that of the experts.

When comparing the three groups of nursing homes, based on their scores assigned by the nonexperts regarding the environmental factors, none of these factors seems to be significantly associated with residents' food intake, after adjustment on the characteristics of the nursing homes presented in Table 1 (Table 4).

\section{Discussion}

This original study performed in nursing homes suggests that the environmental factors could have limited influence on residents' food intake. Indeed, with the exception of the perception by the residents of the meal quantity served, no environmental factors, assessed either by residents or by external individuals, seem to be associated with residents' food intake. When the statistical analyses were performed on the quantity of food consumed (grams) or on the percentage of food consumed in relation to the quantity served (\%), the results followed the same trend. However, this result must be interpreted with caution. If the methodology seems innovative, several limits, mentioned later, must be borne in mind.

The complex relationships between nutrition environment, diet and health outcomes have been conceptualized and widely studied in different settings. ${ }^{24-26}$ Eating takes place in a context of environmental stimuli known as ambience. Various external factors, such as social and physical surroundings, including the presence of other people and sound,

Table 3 Differences in quantity of food consumed (grams) by the residents between the nursing homes with the lowest score, the intermediate score and the highest score, assigned by experts working in the geriatric field, regarding their perception of the dining room, according to six criteria

\begin{tabular}{llll}
\hline Criteria & $\begin{array}{l}\text { Quantity of food consumed } \\
(\mathbf{m e a n} \pm \mathbf{S D}) \text { in the } \text { nursing } \\
\text { homes with the lowest } \\
\text { score assigned by the } \\
\text { experts }(\mathbf{n}=\mathbf{3})\end{array}$ & $\begin{array}{l}\text { Quantity of food consumed } \\
(\text { mean } \pm \mathbf{S D}) \text { in the nursing } \\
\text { homes with the intermediate } \\
\text { score assigned by the } \\
\text { experts }(\mathbf{n}=\mathbf{3})\end{array}$ & $\begin{array}{l}\text { Quantity of food consumed } \\
(\mathbf{m e a n} \pm \mathbf{S D}) \text { in the } \text { nursing } \\
\text { homes with the highest } \\
\text { score assigned by the } \\
\text { experts }(\mathbf{n}=\mathbf{3})\end{array}$ \\
\hline Pleasant setting & $307.1 \pm 43.1$ & $314.4 \pm 58.9$ & $286 \pm 6.31$ \\
The desire to eat in this place & $313.8 \pm 34.5$ & $308.2 \pm 65.7$ & $286 \pm 6.31$ \\
Staff who served & $303.4 \pm 25.8$ & $241.1 \pm 63.8$ & $280.6 \pm 6.6$ \\
Noise & $302.1 \pm 27.2$ & $275.7 \pm 17.5$ & $330.2 \pm 54.1$ \\
The dish looks appetizing & $287.4 \pm 40.3$ & $316.6 \pm 56.6$ & $304 \pm 26.6$ \\
The resident enjoys eating & $287.4 \pm 40.3$ & $300.9 \pm 29.5$ & $319.8 \pm 53.9$ \\
\hline
\end{tabular}

Note: $* P$-value adjusted on the variables related to the organization of the meals presented in Table I: number of meals served per day, preparation of the meal on site or external to the institution, rolling daily menus, seasonal menus, possibility of alternative menus, diet imposed, dinner served at the table, adapted portions, seating plan, fixed times for dining, presence of TV or radio during the dinner, and possibility of having visits during the dinner. 
Table 4 Differences in quantity of food consumed (grams) by the residents, between the nursing homes with the lowest score, the intermediate score, and the highest score, assigned by people who have no particular interest in geriatrics, regarding their perception of the dining room, according to six criteria

\begin{tabular}{llll}
\hline Criteria & $\begin{array}{l}\text { Quantity of food consumed } \\
\text { (mean } \pm \text { SD) in the } \\
\text { nursing homes with the } \\
\text { lowest score assigned by } \\
\text { the nonexperts }(\mathbf{n}=\mathbf{3})\end{array}$ & $\begin{array}{l}\text { Quantity of food consumed } \\
(\mathbf{m e a n} \pm \mathbf{S D}) \text { in the } \\
\text { nursing homes with the } \\
\text { intermediate score assigned } \\
\text { by the nonexperts }(\mathbf{n}=\mathbf{3})\end{array}$ & $\begin{array}{l}\text { Quantity of food consumed } \\
\text { (mean } \pm \mathbf{S D}) \text { in the } \\
\text { nursing homes with the } \\
\text { intermediate score assigned } \\
\text { by the nonexperts }(\mathbf{n}=\mathbf{3})\end{array}$ \\
\hline Pleasant setting & $307.4 \pm 44.9$ & $314.4 \pm 58.9$ & $285.9 \pm 6.36$ \\
The desire to eat in this place & $313.5 \pm 34.2$ & $308.2 \pm 65.7$ & $285.8 \pm 6.37$ \\
Staff who served & $303.2 \pm 25.9$ & $323.8 \pm 67.3$ & $280.6 \pm 6.60$ \\
Noise & $302.1 \pm 27.1$ & $275.6 \pm 17.4$ & $329.9 \pm 54.1$ \\
The dish looks appetizing & $287.4 \pm 40.2$ & $316.6 \pm 56.6$ & $303.7 \pm 26.7$ \\
The resident enjoys eating & $287.4 \pm 40.2$ & $300.6 \pm 29.1$ & $319.6 \pm 54.1$ \\
\hline
\end{tabular}

Note: *P-value adjusted on the variables related to the organization of the meals presented in Table I: number of meals served per day, preparation of the meal on site or external to the institution, rolling daily menus, seasonal menus, possibility of alternative menus, diet imposed, dinner served at the table, adapted portions, seating plan, fixed times for dining, presence of TV or radio during the dinner, and possibility of having visits during the dinner.

temperature, odor, color, time and distraction in the room, could affect food intake and food choice. ${ }^{11}$ Food variables such as the temperature, odor and color of the food could also influence food intake and choice differently. However, the influence of ambience on nutritional health is not fully understood. ${ }^{27}$ One review suggests that the impact of ambience on food intake may be underestimated. ${ }^{27}$ Nevertheless, our results do not allow identifying these food variables or the ambience factors that influence food intake. Indeed, among the six criteria of environmental factors judged positively or negatively by the residents and presented in Table 2 , none of the criteria significantly influenced the quantity of food ingested. The difference compared with the previous study could be explained by the difference in the populations included. This is the first study of its kind conducted in nursing homes. Institutionalized elderly people are probably less sensitive to the factors listed earlier, due to the diminution of sight, hearing, and taste with advancing age.

Only a single factor that could influence food intake was highlighted in our study - the quantity served perceived by the residents. As shown in Figure 1, the more the quantity served is perceived as large by the residents, the less they eat. It is likely that portion size could affect the amount of food eaten, although there is little published research on such effects. ${ }^{28}$ Rolls et al conducted a series of experiments on a single meal among healthy adults. In these studies, subjects consumed more energy when offered the largest portion than when offered the smallest portion. ${ }^{29-31}$ However, it is different among the specific elderly populations. A recent review shows that large portion sizes may be off-putting, particularly where standard portion sizes are used, such as in hospitals or nursing homes. ${ }^{32}$ Large portions or indeed a perceived large portion size may be overwhelming and may actually discourage intake in people who have problems in having a sufficient nutritional intake. ${ }^{33}$ So, serving smaller portions may tempt appetite and promote intake among the elderly. ${ }^{34}$ Small, and even small-looking, packages can thus contribute to increased consumption. ${ }^{35}$ The results here corroborate these studies, and clearly, more studies are needed in nursing homes to determine which portion size can affect food intake, and to clarify such data. It should also be noted that, in general terms, the nine nursing homes included in this study were fairly well rated by the experts, and by the nonexperts of geriatrics, and few differences were observed between them. This could explain the lack of difference in food intake between nursing homes. It is likely that there are nursing homes where more attention is given to meals than in others. Then, it could be claimed that the video approach does not fully reflect reality. Consequently, the panels of experts and nonexperts may have perceived fewer differences regarding the environment (eg, the noise or the brightness is probably not perceived in the same way on the video as on site). Indeed, as indicated in Tables 3 and 4, the perception of the dining room by the experts and the nonexperts, assessed by six different criteria, does not affect the food intake of residents.

In addition to the quantity of food consumed (in grams), it could be interesting to assess the relationship between the energy intakes of the residents (in kcal) and the environmental factors. In our previous work, we have shown that

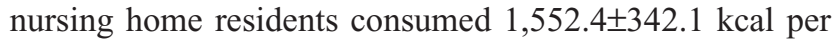
day on average. ${ }^{22}$ The interindividual variation is large, and a 
potential explanation of this variation might be the perception of the environment by the residents. Further investigations could be undertaken to test this hypothesis.

Numerous studies have identified associations between dietary intake and psychoemotional dimension or environmental factors in the general population; however, the majority of these studies do not apply to the nursing home setting. More specific studies should be carried out in a nursing home, in order to guide environmental interventions and policy changes. To move this forward, future research will need to emphasize rigorous study designs and multilevel investigations, examine how associations may vary according to age and other characteristics of population subgroups, develop and evaluate a standard set of measurements for assessing food environments and policies, and improve on current dietary assessment methodologies. ${ }^{36}$

Because the direct behavioral observation becomes indispensable to data gathering and treatment planning, several authors used technologies that can automatically capture and analyze all that they hear and see (ie, video approach), with the potential for significantly affecting clinical care. Observations in a nursing home provide a concrete setting for this challenge, and this technology can be used to assess the environment. Nevertheless, the current study does not demonstrate the need for an interventional study aimed to improve the environment in this specific nursing home population. The results presented in this manuscript corroborate those from previous research by the team that showed that nursing home residents do not eat all the food served but they do maintain a stable weight. ${ }^{22}$

The originality of the methodology used is undeniably the strength of the present study. First, the video approach is new and allows including many experts and nonexperts without their being asked to go to the nursing homes. Consequently, a substantial number of nursing homes, experts, nonexperts and residents were included in the analysis. Moreover, this allows judging the environment without knowing what people are eating. Second, the assessment of food intake was carried out by a food-weighing method, which is the most reliable method that avoids information bias. Third, the fact that experts, nonexperts and residents were questioned is a plus for the study, as it enables seeing if their views coincide. However, this study also has certain limitations. Foremost, due to the selection criteria of the population, residents are probably not representative of a general nursing home population and our results can only be transposed to other geriatric populations with the same selection criteria because of the interindividual differences. This is a bias of external validity. Note that most of the exclusion criteria have been established to ensure the practical feasibility of the study (ie, it would have been impossible to accurately weigh foods separately if residents were fed enterally or parenterally or if they had a modified texture diet). Selection bias arises also from the inclusion of nursing homes because we have included only institutions that were willing to participate in the study. It should also be noted that, in general terms, the nine nursing homes included in this study were fairly well rated and few differences were observed between them. This could explain the lack of difference in food intake between nursing homes. It is likely that there are nursing homes that pay more attention to meals than others. Then, it can also be claimed that the video approach does not fully reflect the reality. Consequently, the general population and the experts may perceive fewer differences regarding the environment (ie, the noise or the brightness is probably not perceived in the same way on the video as on the spot). Another bias may be due to the selection of the panels of experts and nonexperts. Since they are volunteers, respondents may have a conflict of interest that could influence their answers. For example, they could be working in or have a connection with a nursing home and therefore judge the place more leniently. Finally, no specific and/or validated questionnaire to assess the environment of a dining room exists; therefore, the environmental factors measured in the present study are those which were selected on the basis of a scientific literature search. Consequently, the list could be not exhaustive. However, the video support, which is at our disposal, makes it possible to evaluate other possible aspects of the environment in an upcoming analysis.

The results of this study can have important clinical implications. They highlight that caregivers must be attentive to the residents' feelings as this could influence their nutritional status and the general health of the patients. From a public health point of view, calls are made for a more patientcentered health care system. ${ }^{37}$ It becomes critical to define and measure patient perceptions of health care quality and to understand more fully what drives these perceptions.

\section{Conclusion}

This study is the first to evaluate the influence of the environment on food intake in a nursing home setting. It highlighted that only the perception of the residents regarding the quantity of food served appears to be associated with their food intake. However, there is no relationship between the perception of the environment by the nonexperts or by the geriatrics experts and residents' food intake. The relevance of the results of 
this study deserve further investigation. The video approach is original but renders a quantitative interpretation of the results difficult.

\section{Acknowledgments}

We thank all the nursing homes and residents who generously shared their time and experience for the purposes of this project. Fanny Buckinx is supported by a fellowship from the Fonds National de la Recherche Scientifique de Belgique (FNRS) - FRS-FNRS (www. frs-fnrs.be). The abstract of this paper was presented at the "Journée des Doctorants de l'Ecole Doctorale", which took place at the Université Catholique de Louvain in September 2016. The abstract was then published online at http://orbi.ulg.ac.be/handle/2268/203527.

\section{Author contributions}

FB, J-YR, NP, AM, NL, ML, SA and OB have made substantial contributions to conception and design, acquisition of data, or analysis and interpretation of data. FB, SA and $\mathrm{OB}$ have been involved in drafting the manuscript or revising it critically for important intellectual content. All authors contributed toward data analysis, drafting and critically revising the paper and agree to be accountable for all aspects of the work.

\section{Disclosure}

The authors report no conflicts of interest in this work.

\section{References}

1. Donini LM, Savina C, Cannella C. Eating habits and appetite control in the elderly: the anorexia of aging. Int Psychogeriatr. 2003;15(1):73-87.

2. Bell CL, Lee AS, Tamura BK. Malnutrition in the nursing home. Curr Opin Clin Nutr Metab Care. 2015;18(1):17-23.

3. Chen CC, Schilling LS, Lyder CH. A concept analysis of malnutrition in the elderly. $J$ Adv Nurs. 2001;36(1):131-142.

4. Barker LA, Gout BS, Crowe TC. Hospital malnutrition: prevalence, identification and impact on patients and the healthcare system. Int $J$ Environ Res Public Health. 2011;8(2):514-527.

5. Agarwal E, Miller M, Yaxley A, Isenring E. Malnutrition in the elderly: a narrative review. Maturitas. 2013;76(4):296-302.

6. Geurden B, Franck ME, Lopez Hartmann M, Weyler J, Ysebaert D. Prevalence of 'being at risk of malnutrition' and associated factors in adult patients receiving nursing care at home in Belgium. Int $J$ Nurs Pract. 2015;21(5):635-644.

7. Vanderwee K, Clays E, Bocquaert I, Gobert M, Folens B, Defloor T. Malnutrition and associated factors in elderly hospital patients: a Belgian cross-sectional, multi-centre study. Clin Nutr. 2010;29(4):469-476.

8. Verbrugghe M, Beeckman D, Van Hecke A, et al. Malnutrition and associated factors in nursing home residents: a cross-sectional, multicentre study. Clin Nutr. 2013;32(3):438-443.

9. Pirlich M, Schutz T, Norman K, et al. The German hospital malnutrition study. Clin Nutr. 2006;25(4):563-572.

10. van Bokhorst-de van der Schueren MA, Guaitoli PR, Jansma EP, de Vet HC. A systematic review of malnutrition screening tools for the nursing home setting. J Am Med Dir Assoc. 2014;15(3): $171-184$.
11. Wansink B. Environmental factors that increase the food intake and consumption volume of unknowing consumers. Annu Rev Nutr. 2004; $24: 455-479$

12. Stroebele-Benschop N, Depa J, de Castro JM. Environmental strategies to promote food intake in older adults: a narrative review. $J$ Nutr Gerontol Geriatr. 2016;35(2):95-112.

13. Elmstahl S, Blabolil V, Fex G, Kuller R, Steen B. Hospital nutrition in geriatric long-term care medicine. I. Effects of a changed meal environment. Compr Gerontol A. 1987;1(1):29-33.

14. Meiselman HL. Methodology and theory in human eating research. Appetite. 1992;19(1):49-55.

15. McDaniel JH, Hunt A, Hackes B, Pope JF. Impact of dining room environment on nutritional intake of Alzheimer's residents: a case study. Am J Alzheimers Dis Other Demen. 2001;16(5):297-302.

16. Green SH, Glanz K. Development of the perceived nutrition environment measures survey. Am J Prev Med. 2015;49(1):50-61.

17. Jilcott SB, Laraia BA, Evenson KR, Ammerman AS. Perceptions of the community food environment and related influences on food choice among midlife women residing in rural and urban areas: a qualitative analysis. Women Health. 2009;49(2-3):164-180.

18. Zenk SN, Lachance LL, Schulz AJ, Mentz G, Kannan S, Ridella W. Neighborhood retail food environment and fruit and vegetable intake in a multiethnic urban population. Am J Health Promot. 2009;23(4): $255-264$.

19. Fox MK, Dodd AH, Wilson A, Gleason PM. Association between school food environment and practices and body mass index of US public school children. J Am Diet Assoc. 2009;109(2 suppl):S108-S117.

20. Hill AJ, Rogers PJ, Blundell JE. Techniques for the experimental measurement of human eating behaviour and food intake: a practical guide. Int J Obes Relat Metab Disord. 1995;19(6):361-375.

21. Appleton KM. Increases in energy, protein and fat intake following the addition of sauce to an older person's meal. Appetite. 2009;52(1): 161-165.

22. Buckinx F, Allepaerts S, Paquot N, et al. Energy and nutrient content of food served and consumed by nursing home residents. J Nutr Health Aging. 2017;21(6):727-732.

23. Fermanian J. Validation des échelles d'évaluation en médecine physique et de réadaptation : comment apprécier correctement leurs qualités psychométriques. [Validation of assessment scales in physical medicine and rehabilitation: how are psychometric properties determined?]. Ann Readapt Med Phys. 2005;48(6):281-287.

24. Glanz K, Sallis JF, Saelens BE, Frank LD. Healthy nutrition environments: concepts and measures. Am J Health Promot. 2005;19(5):330-333,ii.

25. Story M, Kaphingst KM, Robinson-O’Brien R, Glanz K. Creating healthy food and eating environments: policy and environmental approaches. Annu Rev Public Health. 2008;29:253-272.

26. Caspi CE, Sorensen G, Subramanian SV, Kawachi I. The local food environment and diet: a systematic review. Health Place. 2012;18(5): $1172-1187$.

27. Stroebele N, De Castro JM. Effect of ambience on food intake and food choice. Nutrition. 2004;20(9):821-838.

28. National Academy of Sciences. In: Marriott BM, editor. Not Eating Enough: Overcoming Underconsumption of Military Operational Rations. Washington DC: National Academy of Sciences; 1995.

29. Rolls BJ, Morris EL, Roe LS. Portion size of food affects energy intake in normal-weight and overweight men and women. Am J Clin Nutr. 2002;76(6):1207-1213.

30. Rolls BJ, Roe LS, Meengs JS, Wall DE. Increasing the portion size of a sandwich increases energy intake. J Am Diet Assoc. 2004;104(3): 367-372.

31. Rolls BJ, Roe LS, Kral TV, Meengs JS, Wall DE. Increasing the portion size of a packaged snack increases energy intake in men and women. Appetite. 2004;42(1):63-69.

32. Pilgrim AL, Robinson SM, Sayer AA, Roberts HC. An overview of appetite decline in older people. Nurs Older People. 2015;27(5):29-35.

33. Huffman GB. Evaluating and treating unintentional weight loss in the elderly. Am Fam Physician. 2002;65(4):640-650. 
34. Nieuwenhuizen WF, Weenen H, Rigby P, Hetherington MM. Older adults and patients in need of nutritional support: review of current treatment options and factors influencing nutritional intake. Clin Nutr. 2010;29(2):160-169.

35. Coelho T, Paul C, Gobbens RJ, Fernandes L. Frailty as a predictor of short-term adverse outcomes. PeerJ. 2015;3:e1121.
36. Larson N, Story M. A review of environmental influences on food choices. Ann Behav Med. 2009;38(suppl 1):S56-S73.

37. Sofaer S, Firminger K. Patient perceptions of the quality of health services. Annu Rev Public Health. 2005;26:513-559.

\section{Publish your work in this journal}

Clinical Interventions in Aging is an international, peer-reviewed journal focusing on evidence-based reports on the value or lack thereof of treatments intended to prevent or delay the onset of maladaptive correlates of aging in human beings. This journal is indexed on PubMed Central, MedLine,
CAS, Scopus and the Elsevier Bibliographic databases. The manuscript management system is completely online and includes a very quick and fair peer-review system, which is all easy to use. Visit http://www.dovepress. com/testimonials.php to read real quotes from published authors. 